\title{
점강우모형을 이용한 미래 시간강우자료 생산 및 미래 강우유출수 분석
}

\section{Future Hourly Rainfall Data Production using Point Rainfall Model and Future Stormwater Analysis}

\author{
차우영* - 이옥정** · 최정현*** - 이정훈**** . 김상단***** \\ Cha, Wooyoung ${ }^{*}$, Lee, Okjeong ${ }^{* *}$, Choi, Jeonghyeon ${ }^{* * *}$, Lee, Jeonghoon ${ }^{* * * *}$, and Kim, Sangdan ${ }^{* * * * *}$
}

\begin{abstract}
In this study, future hourly rainfall data were generated from future daily rainfall data driven from climate models using a point rainfall model. In addition, the EPA-SWMM model was constructed for the Noksan Industrial Complex in Busan and the future hourly rainfall data were used to simulate future stormwater. As a result of the hourly rainfall projection, it was confirmed that the trend in the case of extreme rainfall events would increased in Busan area to the future, but Seoul area would tended to decrease in the future. As a result of projecting the future stormwater in Busan, it was found that the stormwater were likely to increase with the future, and the flood risk and non-point pollutant load resulting from this increase were also likely to increase. In the case of urban streams in Busan in the future, the number of days when stormwater occurs is likely to increase, so that it was expected that the number of days when water flows into urban streams would increase.
\end{abstract}

Key words : Climate Change, EPA-SWMM, Point Rainfall Model, Stormwater

\section{요 지}

본 연구에서는 점강우모델을 이용하여 기후모델에서 생산된 미래 일 강우자료로부터 시간강우자료를 생성하였다. 또한 부산 녹산공단 지역을 대상으로 EPA-SWMM모형을 구축한 후, 생산된 미래 시간강우자료를 이용하여 미래 강우유출수를 모의하였다. 연구 결과, 강우의 계급구간으로 보았을 때, 극한 사상의 경우에는 부산지역은 미래로 갈수록 증가하였으나 서울지역은 미래로 갈수록 감소하는 경향을 확인하였다. 부산의 미래 강우유출수를 전망해본 결과, 미래로 갈수록 강우유출수가 증가하였으 며, 따라서 이로 인한 홍수위험도 및 비점오염부하량이 증가할 것으로 파악되었다. 또한 미래 부산의 도시 하천의 경우 현재보다 강우유출수가 발생되는 기간이 증가하여 건천이 될 확률은 다소 감소할 가능성이 있을 것으로 전망되었다.

핵심용어 : 기후변화, EPA-SWMM, 점강우모형, 강우유출수

\section{1. 서 론}

지구의 환경과 기후는 여러 가지 요인에 의해 변화하고
있고, 기후변화로 인해 수문학적 극한사상의 규모와 빈도가 변화한다는 사실은 이미 국제적으로 인정되고 있는 과학적 사실이다(Kim et al., 2008). 특히 도시지역의 경우 기후변화

*정회원, 부경대학교 지구환경시스템과학부 환경공학전공 석사과정(E-mail: epik_tania@naver.com)

Member, Master Course Student, Division of Earth Environmental System Science (Major of Environmental Engineering), Pukyong National University

**정회원, 부경대학교 지구환경시스템과학부 환경공학전공 박사과정(E-mail: lover1804@nate.com)

Member, Ph.D. Student, Division of Earth Environmental System Science (Major of Environmental Engineering), Pukyong National University

***정회원, 부경대학교 지구환경시스템과학부 환경공학전공 석사과정(E-mail: jeonghyeon202@naver.com)

Member, Master Course Student, Division of Earth Environmental System Science (Major of Environmental Engineering), Pukyong National University

****정회원, 부경대학교 환경연구소(E-mail: bravo281@hanmail.net)

Member, Institute of Environmental and Marine Science, Pukyong National University

*****교신저자, 정회원, 부경대학교 환경공학과 교수(Tel: +82-51-629-6529, Fax: +82-51-629-6523, E-mail: skim@pknu.ac.kr)

Corresponding Author, Member, Professor, Department of Environmental Engineering, Pukyong National University 
에 따른 강우사상의 변화에 따라서 강우유출수의 변화 또한 예상된다(Zahmatkesh et al., 2014). 따라서 기후변화의 영향 을 고려한 도시지역의 배수구조물 설계 및 수질관리대책에 대한 연구가 활발히 진행 중이다. 국내외 대부분의 연구에서 기후변화의 영향을 고려하기 위하여 미래 기후자료를 사용 하고 있는데, 이러한 미래 기후자료는 전 지구 기후모델 (Global Climate Model, GCM) 혹은 지역기후모델(Regional Climate Model, RCM)을 통하여 획득된다(Kim et al., 2008; Lee et al., 2016).

하지만 이러한 미래 기후자료는 주로 일 단위의 자료로 제공되기 때문에, 실제 배수구조물을 설계하거나 도시하천 의 수질관리대책에 적용하기에는 어려움이 따르게 된다. 도시 배수분구와 같이 면적이 작은 지역의 경우에는 최소한 시간단위의 강우자료가 필요하기 때문이다. 따라서 기후변 화의 영향을 반영하여 도시 배수분구의 배수구조물을 설계 하거나 도시하천의 수질관리대책을 수립하기 위해서는 일 단위로 주어지는 강우자료를 시간단위의 강우자료로 다운 스케일해야 할 필요성이 있게 된다.

이에 본 연구에서는 군집 기반의 추계학적 점강우모델인 Neyman-Scott 구형 펄스 모델(Neyman-Scott Rectangular Pulse Model, NSRPM)을 이용하여 미래 일 강우자료를 시간 강우자료로 다운스케일하고자 한다. Lee et al.(2017)은 일 강우량자료의 시간적 다운스케일을 위해 기존 NSRPM의 강우세포의 확률밀도함수인 지수분포를 3-변수 혼합 지수분 포를 전환한 NSRPM(Neyman-Scott Rectangular Pulse Model with 3-Parameter Mixed Exponential Distribution, 이하 NSRPM3)을 개발한 후, 이를 이용하여 강릉, 부산, 목포, 인천 지역의 일 강우자료로부터 시간강우자료를 생산 한 결과, 기존의 NSRPM보다 모델성능이 더 우수함을 살펴 볼 바 있다.

따라서 본 연구에서는 Lee et al.(2017)의 연구를 통해 개발된 $\mathrm{NSRPM} 3$ 을 이용하여 기상청 RCM의 RCP(Representative Concentration Pathway, RCP) 8.5 기후변화 시나리오로부터 획득된 부산지역의 일 강우자료를 다운스케일하여 시간단 위 강우자료를 생성해보고자 하였다. 또한 도시유출해석모 델인 EPA-Storm Water Management Model(EPA-SWMM) 을 부산 녹산공단을 대상으로 구축한 후, 생산된 시간단위 강우자료를 적용하여 미래 강우유출수의 변화양상을 살펴 보고자 하였다. 연구의 다양성을 위해 부산지역 뿐만 아니라 서울지역의 일 강우자료를 다운스케일 하여 시간단위 강우 자료를 생성하여 미래 강우량변화를 살펴보고자 하였다.

\section{2. 연구방법}

\section{1 기상청 미래 기후정보}

기상청에서는 AR5에 따른 4개의 RCP 시나리오( $2.6,4.5$, $6.0,8.5)$ 의 미래 기후자료를 일 단위로 제공하고 있다. 공간
해상도로 이들 자료를 구분하면, 영국 기상청 해들리 센터의 기후변화 예측모델 HadGEM2-AO를 이용하여 생산한 135 $\mathrm{km}$ 공간 해상도의 전 지구자료, HadGEM2-AO의 결과를 바탕으로 지역기후모델인 HadGEM3-RA를 구동하여 12.5 $\mathrm{km}$ 공간해상도로 생산된 한반도 지역자료, $12.5 \mathrm{~km}$ 공간 해상도 자료를 이용하여 통계적 다운스케일링 기법을 이용 하여 $1 \mathrm{~km}$ 공간 해상도로 생산된 남한 상세자료로 구분할 수 있다. 이 중 본 연구에서는 가장 공신력이 높은 12.5 $\mathrm{km}$ 공간 해상도 자료를 이용하였으며, 적용대상지역인 부산 과 서울에 해당하는 격자에서 미래 일 강우자료와 일평균 기온자료를 추출하였다.

$\mathrm{GCM}$ 이나 RCM 등에서 생산되는 기후모의결과는 기후모델 자체의 여러 가지 한계로 인하여 현재기후 모의자료와 이에 대응하는 과거 관측 자료 사이에 서로 일치하지 않는 편이가 발생하게 된다. 따라서 다양한 편이보정(Bias-Correction) 과정을 수행하여 모델로부터 도출된 미래 기후자료를 보정 하여 보정된 미래 기후자료를 사용하는 것이 일반적이다. 본 연구에서는 $\mathrm{KDDM}($ Kernel Density Distribution Mapping, $\mathrm{KDDM}$ ) 방법을 이용하여 편이를 보정하고자 하였다. $\mathrm{KDDM}$ 방법은 $\mathrm{RCM}$ 모의결과의 누가확률밀도함수 $(\mathrm{CDF})$ 를 같은 기간(월 단위) 관측 자료의 누가확률밀도함수에 Quantile mapping 하는 방식이다(Kim et al., 2011). 강우자료의 편이 보정을 실시할 경우에는 강우일수에 대한 보정이 우선적으 로 수행된 후, $\mathrm{KDDM}$ 방법이 적용되어졌다. 예를 들어 8월의 관측 강우자료 $x_{o}$ 에 대한 누가확률밀도 함수를 $F_{o}\left(x_{o}\right)$, 현재 기간 모의자료 $x_{p}$ 에 대한 누가확률밀도 함수를 $F_{p}\left(x_{p}\right)$ 라고 할 때, $x_{p}$ 의 편이보정 된 값 $x_{p}{ }^{\prime}$ 는 $F_{o}{ }^{-1}\left[F_{p}\left(x_{p}\right)\right]$ 로 구할 수 있다. 여기서 $F_{o}^{-1}$ 은 $F_{o}$ 의 역함수를 의미하고, 이러한 과정을 통해 관측 강우자료와 편이보정 된 현재기간 모의자 료의 다양한 통계량이 서로 일치하게 된다. 이를 바탕으로 미래기간 모의자료 $F_{f}$ 의 편이보정 된 값 $F_{f}{ }^{\prime}$ 는 $F_{o}{ }^{-1}\left[F_{p}\left(x_{f}\right)\right]$ 로 추출하였다.

\subsection{NSRPM3}

$\mathrm{NSRPM}$ 은 군집 점 과정 모형으로, 3개의 독립적인 추계학적 과정으로 강우의 발생을 모의한다. 1) 호우의 발생을 지배하는 과정, 2) 각각의 호우에서 발생되는 강우세포의 수를 좌우하 는 과정, 3) 강우세포의 시간적인 위치를 결정하는 과정.

이를 바탕으로 NSRPM은 아래의 절차를 순차적으로 진행 함으로써 연속적인 강우시계열을 모의하게 된다.

(1) NSRPM은 총 5 개의 확률과정으로 구성된다. 우선 포아송 과정(Poisson process)을 이용하여 호우사상의 시작 위치가 결정된다. 이 때, 포아송 과정의 매개변수 로 $\lambda$ 가 사용된다.

(2) 발생된 호우사상의 시작 위치를 기점으로 포아송 분포 를 이용하여 해당 호우사상이 보유하는 강우세포의 
수가 결정된다. 이 때, 포아송 분포의 매개변수로 $E[\nu]$ 가 사용된다.

(3) 강우세포의 시간적인 발생 위치는 호우사상이 발생된 시간적인 위치와는 독립적으로 구분되어 모의되는데, 주로 지수(Exponential)분포를 이용하여 각 강우세포 의 위치가 결정된다. 이 때, 지수분포형의 매개변수로 $\beta$ 가 사용된다.

(4) 강우세포의 위치가 결정되면 각 강우세포들의 강우강 도는 지수분포를 이용하여 결정된다. 이 때, 분포형의 매개변수로 $\xi$ 가 사용된다.

(5) 각 강우세포의 지속시간 또한 지수분포를 이용하여 결정되는데, 이 때 지수분포형의 매개변수로 $\eta$ 가 사용 된다.

(6) 모든 호우사상에 대한 강우세포들에 대한 강우강도 및 지속시간을 이용하여 서로 중첩하게 되면 일련의 연속적인 강우시계열을 얻게 된다.

본 연구에서는 앞서 언급한 NSRPM에서 강우세포의 강우 강도가 지수분포를 따른다고 가정하는 대신에 3-변수 혼합 지수분포를 따른다고 가정하였다. Eq. (1)에 3-변수 혼합 지수분포에 대한 식을 나타내었다.

$$
f(x)=\frac{\alpha}{\xi} e^{-\frac{x}{\xi}}+\frac{1-\alpha}{\theta} e^{-\frac{x}{\theta}}
$$

여기서 $x$ 는 강우세포의 강우강도이며, $\alpha, \xi, \theta$ 는 3-변수 혼합 지수분포의 매개변수이다. 결국 3-변수 혼합 지수분포 는 매개변수 $\xi$ 의 지수분포와 매개변수 $\theta$ 의 두 개의 지수분포 가 가중 평균적으로 결합된 분포임을 알 수 있다. 강우세포의 강우강도 1 차 및 2 차 모멘트는 다음과 같다.

$$
\begin{aligned}
& E[x]=\alpha \xi+(1-\alpha) \theta \\
& E\left[x^{2}\right]=2 \alpha \xi^{2}+2(1-\alpha) \theta^{2}
\end{aligned}
$$

참고로 $\alpha$ 를 1 로 지정하게 되면 $\theta$ 값과 상관없이 기존의 NSRPM과 동일한 모형이 된다.

Rodriguez-Iturbe(1986)에 따르면 $h$-시간 간격으로 중첩 됨 없이 집성된 강우시계열 $Y_{i}^{(h)}$ 의 평균과 분산에 관한 식은 다음과 같다.

$$
\begin{aligned}
E\left[Y_{i}^{(h)}\right]= & \frac{\lambda E[\nu] E[x] h}{\eta} \\
\operatorname{Var}\left[Y_{i}^{(h)}=\right. & \frac{\lambda}{\eta^{3}}\left(\eta h-1+e^{-\eta h)}\left\{E[\nu] E\left[x^{2}\right]+\frac{\left(E^{2}[v]-1\right) E^{2}[x] \beta^{2}}{\beta^{2}-\eta^{2}}\right\}\right. \\
& -\frac{\lambda\left(\beta h-1+e^{-\beta h}\right)\left(E^{2}[v]-1\right) E^{2}[x]}{\beta\left(\beta^{2}-\eta^{2}\right)}
\end{aligned}
$$

또한 $Y_{i}^{(h)}$ 시계열의 무 강우 확률은 다음과 같이 유도된다 (Cowpertwait et al., 1996).

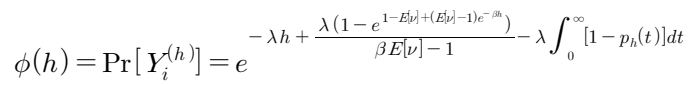

$$
\begin{aligned}
& p_{h}(t)=\left(e^{-\beta(t+h)}+1-\frac{\eta e^{-\beta t}-\beta e^{-\eta t}}{\eta-\beta}\right) e^{-\frac{(E[\nu]-1) \beta\left(e^{-\beta t}-e^{-\eta t}\right)}{\eta-\beta}-(E[\nu]-1) e^{-\beta}+(E[\nu]-1) e^{-\beta(t+h)}}
\end{aligned}
$$

강우가 연속적으로 이어질 확률 $\phi_{w w}(h)$ 및 무 강우가 연속 적으로 이어질 확률 $\phi_{d d}(h)$ 은 아래와 같이 유도될 수 있다.

$$
\begin{aligned}
& \phi_{w w}(h)=\frac{1-2 \phi(h)+\phi(2 h)}{1-\phi(h)} \\
& \phi_{d d}(h)=\frac{\phi(2 h)}{\phi(h)}
\end{aligned}
$$

Fig. 1에 NSRMP3의 구성도를 도식화하여 나타내었다.

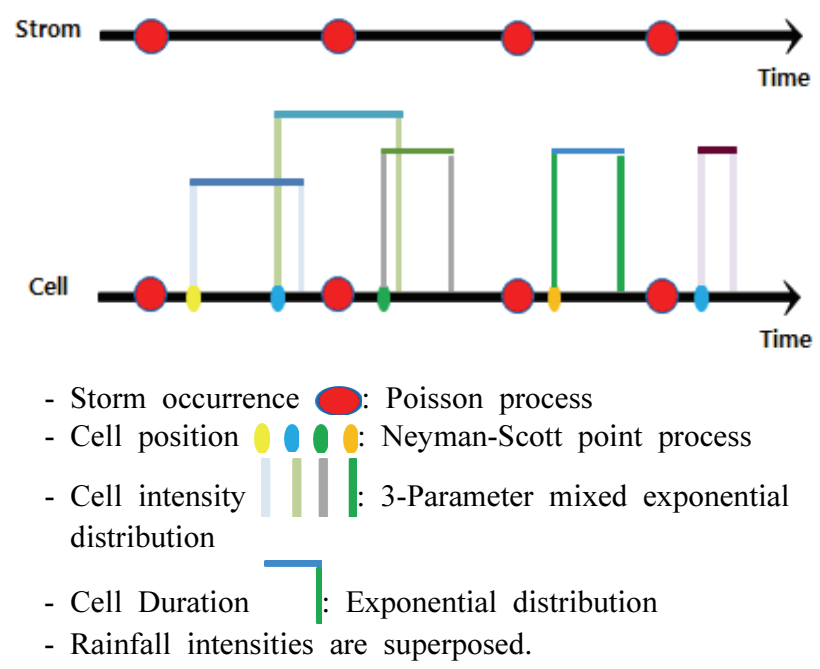

Fig. 1. A Schematic Depiction of NSRPM3.

\section{3 매개변수 추정}

Cowpertwait et al.(1996)에 따르면, 일 강우량 자료만으로 NSRPM의 매개변수를 추정하고자 할 경우에는 다음과 같은 절차에 따라 수행할 것으로 추천하고 있으므로, 본 연구에서 도 이를 토대로 매개변수를 추정하고자 하였다.

(1) 관측 자료로부터 $E\left[Y_{i}^{1 h}\right], \operatorname{Var}\left[Y_{i}^{24 h}\right], \phi_{w w}(24 h)$, $\phi_{d d}(24 h), \phi(24 h)$ 을 계산. 이 때, $E\left[Y_{i}^{1 h}\right]$ 는 단순히 $E\left[Y_{i}^{24 h}\right]$ 를 24 로 나누어줌으로써 계산 가능하므로, 일 자료로부터 추정 가능 
(2) 집성시간 1 시간, 3 시간, 6 시간, 12 시간 관측 강우자료 로부터 집성시간별 분산을 계산하고, 이들 값과 집성 시간 24 시간(즉, 일 자료) 관측 자료의 분산과의 회귀모 형 구성

(3) 위의 9개의 관측 통계량을 이용하여 아래 Eq. (10)과 같은 목적함수 $S$ 을 최소화하는 NSRPM3의 7개 매개 변수 $(\lambda, E[\nu], \beta, \eta, \xi, \theta, \alpha)$ 를 추정

$$
S=\sum_{i=1}^{m} w_{i}\left(1-\frac{f_{i}}{\hat{f}_{i}}\right)^{2}
$$

여기서 $\hat{f}_{i}$ 는 관측 자료로부터 구한 $i$ 번째 통계량이며, $f_{i}$ 는 NSRPM3 의 매개변수로 이루어진 $i$ 번째 통계량으로, Eqs. (1)-(9)를 이용하여 표현된다. $w_{i}$ 는 $i$ 번째 통계량의 가중치로 서, 통계량마다 가중치를 다르게 설정할 수 있다. 본 연구에서 는 Cowpertwait et al.(1996)과 동일하게 평균에 가중치 100을 부여하였으며, 나머지 통계량인 1 시간 분산, 3 시간 분산, 6시간 분산, 12 시간 분산, 24 시간 분산, 24 시간 무강우 확률, 24시간 강우-강우 전이확률, 24 시간 무강우-무강우 전이 확률의 가중치는 1 로 할당하였다.

\section{4 미래 강우유출수}

부산 녹산공단지역은 부산광역시 강서구 송정동에 위치
한 국가산업단지로서, 본 연구에서는 그 중 일부지역(13,000 $m^{2}$ )을 대상구역으로 선정하였다. 대상구역은 거의 대부분 불투수 지역으로 되어있으며, 토지이용상태는 모두 공업지 역으로 이루어져 있다(Choe et al., 2016). 이러한 토지특성을 적용하여 EPA-SWMM을 구축할 때, 대상구역을 건물과 비 건물 부분으로 나누어 모형을 구축하였고, $100 \%$ 불투수 면적으로 설정하였다.

Fig. 2는 대상지역의 위성사진과 EPA-SWMM으로 구성 한 소유역도를 보여주고 있다. 기후변화에 대한 강우유출 수의 평균적인 거동을 살펴보기 위해서는 장기간 모의가 필요하게 되므로, 이에 따라 증발산의 경우는 Thornthwaite 방법을 이용하여 월평균 증발산량을 계산하여 모델에 입력 하였다. 따라서 미래 강우유출수를 모의할 경우에는 RCP 8.5 시나리오의 평균기온 전망결과로부터 Thornthwaite 방법을 이용하여 미래 월평균 증발산을 산정하여 미래 강우유출수를 모의하였다. 모델의 매개변수 추정을 위하여 EPA-SWMM과 Matlab 연계모듈을 이용하여 실측된 강우유 출수 유출고와 모의된 강우유출수 유출고를 비교하였으며, 목적함수는 Gupta et al.(2009)에 의해 제안된 Kling-Gupta Efficiency를 사용하여 목적함수가 1에 가까워지는 매개 변수들의 값을 자동으로 추정하게 하였다. 추정된 매개 변수는 다음 Table 1 과 같으며 소유역별로 매개변수를 추정하였다.
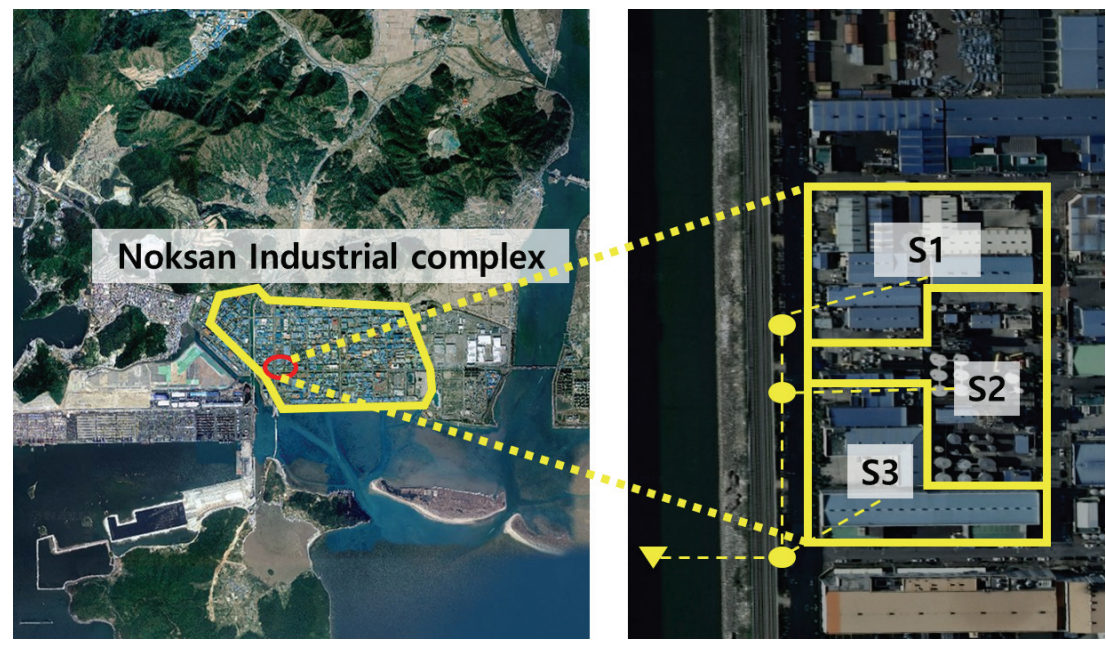

Fig. 2. Target Study Area

Table 1. Parameters in Busan Noksan of EPA-SWMM

\begin{tabular}{c|c|c|c|c}
\hline \multirow{2}{*}{ Subcatchments } & \multicolumn{4}{|c}{ Parameter } \\
\cline { 2 - 5 } & Slope (\%) & N-Imperv (\%) & Dstore-Imperv (mm) & Zero-Imperv (\%) \\
\hline S1 & 0.01 & 0.024 & 2.5356 & 0.0156 \\
\hline S2 & 0.01 & 0.024 & 2.5356 & 0 \\
\hline S3 & 0.01 & 0.024 & 2.5356 & 0 \\
\hline
\end{tabular}




\section{3. 연구결과}

\section{1 편이보정 결과}

미래 기후변화 시나리오를 적용하기에 앞서 본 연구에서 사용한 편이보정된 미래자료의 타당성을 살펴보기 위하여 부산과 서울지역의 관측 기상자료(1981-2005)를 사용하여 편이보정의 결과를 Fig. 3에 나타내었다. 월 평균 강우량의 경우 부산과 서울지역 모두 8 월이 관측 자료와 편이보정 전의 자료가 크게 차이가 났다. 부산지역의 8 월 관측 평균 강우량 값은 $273.5 \mathrm{~mm}$, 편이보정 전 현재 기후모의 자료의 8 월 강우량 값은 $108.8 \mathrm{~mm}$ 로 약 $164.7 \mathrm{~mm}$ 차이가 났다. 서울지역의 8 월 관측 평균 강우량 값은 $377.2 \mathrm{~mm}$, 편이보정 전 강우량 값은 $142.1 \mathrm{~mm}$ 로 약 $235.1 \mathrm{~mm}$ 차이가 났다. 부산과 서울지역의 8 월 편이보정 후 값은 $274.3 \mathrm{~mm}, 376.6$ $\mathrm{mm}$ 로 관측 자료를 잘 모의하고 있음을 확인할 수 있다.

Fig. 4는 편이보정을 실시한 평균기온을 이용하여 Thornwaite 방법으로 산정한 월별 잠재증발산량을 나타내었다. 편이보 정 된 현재기후 모의자료의 잠재증발산량이 관측 자료로 구한 잠재증발산량을 우수하게 재현하고 있으며, 미래로 갈수록 잠재증발산량이 증가하고 있음을 아울러서 확인할 수 있다. 이는 미래의 기온의 점차적으로 증가함에 따른 결과로서, 잠재증발산량이 커짐에 따라 미래의 강우유출수
도 영향을 받을 수 있을 것으로 분석되었다.

\subsection{NSRPM3 검증}

본 절에서는 부산과 서울의 관측자료(이하 $\mathrm{Obs)}$ 의 일 강우자료를 바탕으로 모의한 관측모의자료(이하 Obs N3)의 비교를 통해 NSRPM3의 성능을 검증하고자 하였다. 또한 기후모형으로부터 도출된 현재기간자료(Present)의 일 자료 를 바탕으로 NSRPM3를 이용하여 모의한 현재기간 모의자 료(이하 Pre N3)와의 비교를 통해 미래 일 강우자료에서 시간강우자료 생성에 대한 타당성을 검증하고자 하였다.

Fig. 5는 월별 집성시간 1시간 평균, 3 시간 분산에 대한 비교를 보여주고 있다. Fig. 5에서 살펴볼 수 있듯이, Obs를 통해 모의한 Obs N3의 월별 집성시간 1 시간 평균, 3 시간 분산이 $\mathrm{Obs}$ 를 잘 재현함을 볼 수 있다. 이는 NSRPM3라는 모형을 통해 일 강우자료에서 시간강우자료로 다운스케일 의 타당성을 검증할 수 있는 것으로 판단된다. 또한 $\mathrm{RCM}$ 에 서 제공하는 현재기간 모의자료를 통해 생산한 Pre N3 또한 Obs를 우수하게 재현하고 있으므로, 미래 일 강우자료로부 터 시간단위 강우자료로 다운스케일하는 것이 타당성을 가질 수 있을 것으로 판단하였다.

Table 2는 부산과 서울지역의 집성시간별 통계특성을 보여주고 있다. 계절별 특성을 확인하기 위해 봄, 여름, 가을,

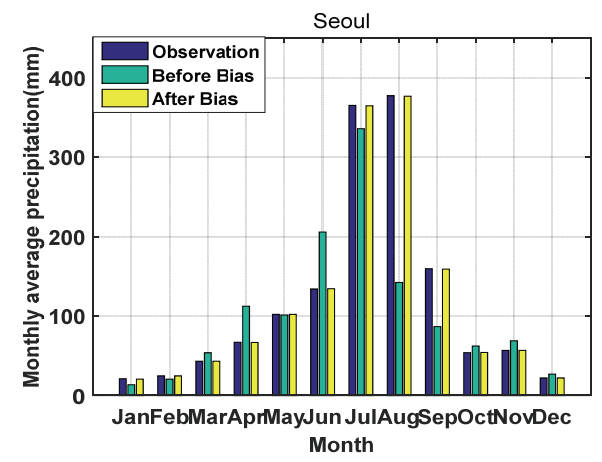

(b) Seoul

Fig. 3. Bias-correction Results

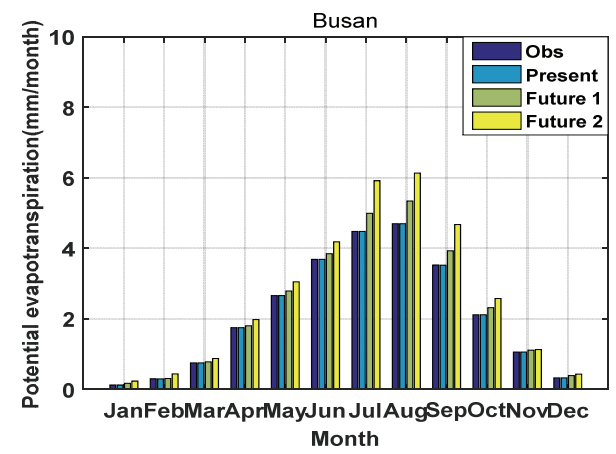

Fig. 4. Monthly Potential Evapotranspiration 


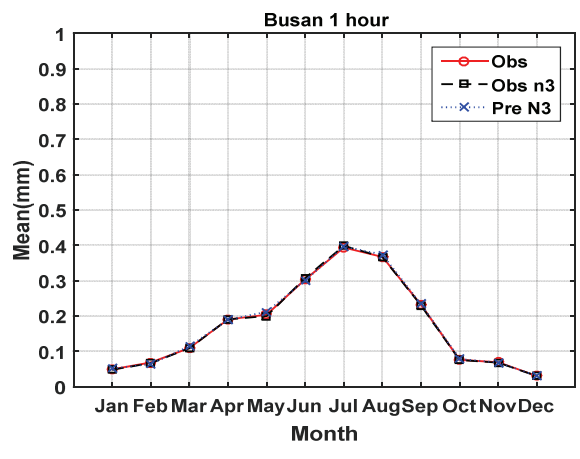

(a) Busan 1-hour Mean

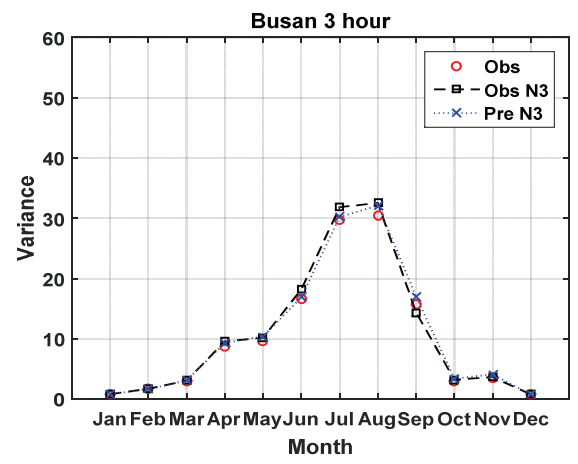

(c) Busan 3-hour Variance

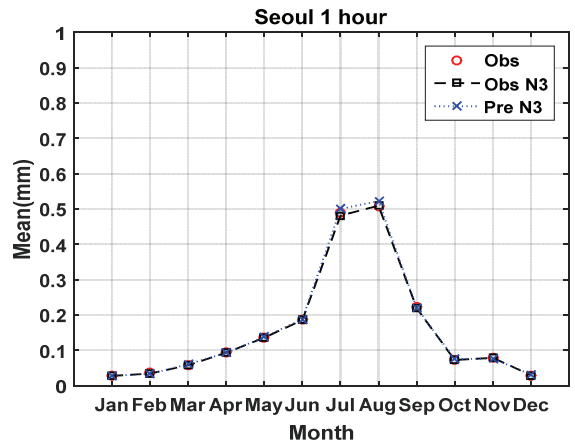

(b) Seoul 1-hour Mean

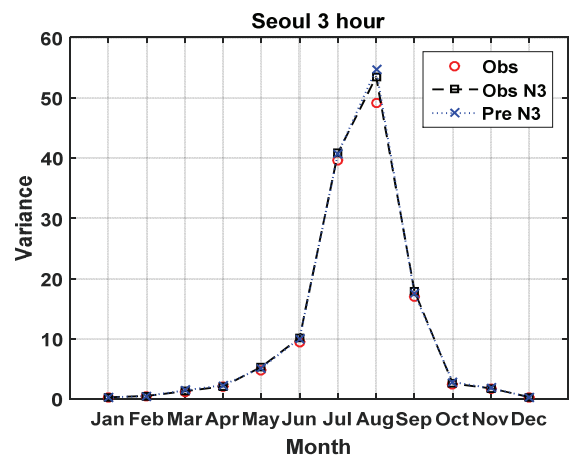

(d) Seoul 3-hour Variance

Fig. 5. Comparison of Mean and Variance of Observation and Generation Data by Month

Table 2. Statistical Characteristics by Aggregation Time on Busan and Seoul

\begin{tabular}{|c|c|c|c|c|c|c|c|}
\hline Mth & Busan & $E\left[Y_{i}^{1 h}\right]$ & $\phi_{w w}(3 h)$ & $\phi_{d d}(3 h)$ & $\operatorname{Var}\left[Y_{i}^{6 h}\right]$ & $\operatorname{Var}\left[Y_{i}^{12 h}\right]$ & $\phi(24 h)$ \\
\hline \multirow{3}{*}{ Feb. } & Obs & 0.0671 & 0.6707 & 0.9729 & 5.3613 & 14.8955 & 0.7957 \\
\hline & Obs N3 & 0.0668 & 0.6747 & 0.9722 & 5.3879 & 14.7424 & 0.7798 \\
\hline & Pre N3 & 0.0646 & 0.7817 & 0.9857 & 5.2341 & 14.4455 & 0.8526 \\
\hline \multirow{3}{*}{ May } & Obs & 0.2041 & 0.7596 & 0.9646 & 32.3047 & 91.9994 & 0.6942 \\
\hline & Obs N3 & 0.1998 & 0.7076 & 0.9663 & 34.0173 & 100.8625 & 0.7262 \\
\hline & Pre N3 & 0.2123 & 0.7357 & 0.9657 & 34.4611 & 102.0735 & 0.7168 \\
\hline \multirow{3}{*}{ Aug. } & Obs & 0.3676 & 0.6986 & 0.9416 & 94.9176 & 247.2513 & 0.6206 \\
\hline & Obs N3 & 0.3673 & 0.6565 & 0.9413 & 99.2630 & 264.7730 & 0.6248 \\
\hline & Pre N3 & 0.3741 & 0.6551 & 0.9511 & 96.7251 & 257.0079 & 0.6721 \\
\hline \multirow{3}{*}{ Nov. } & Obs & 0.0694 & 0.6409 & 0.9752 & 12.3040 & 30.1664 & 0.8080 \\
\hline & Obs N3 & 0.0681 & 0.6384 & 0.9801 & 11.4733 & 31.3311 & 0.8349 \\
\hline & Pre N3 & 0.0686 & 0.6157 & 0.9848 & 13.0312 & 35.7865 & 0.8646 \\
\hline Mth & Seoul & $E\left[Y_{i}^{1 h}\right]$ & $\phi_{w w}(3 h)$ & $\phi_{d d}(3 h)$ & $\operatorname{Var}\left[Y_{i}^{6 h}\right]$ & $\operatorname{Var}\left[Y_{i}^{12 h}\right]$ & $\phi(24 h)$ \\
\hline \multirow{3}{*}{ Feb. } & Obs & 0.0353 & 0.6404 & 0.9748 & 1.6818 & 4.2478 & 0.7957 \\
\hline & Obs N3 & 0.0353 & 0.6756 & 0.9823 & 1.7482 & 4.9559 & 0.8398 \\
\hline & Pre N3 & 0.0335 & 0.6978 & 0.9849 & 1.6663 & 4.7548 & 0.8574 \\
\hline \multirow{3}{*}{ May } & Obs & 0.1372 & 0.7208 & 0.9635 & 14.3228 & 43.6908 & 0.7097 \\
\hline & Obs N3 & 0.1372 & 0.6598 & 0.9676 & 16.1914 & 45.0596 & 0.7394 \\
\hline & Pre N3 & 0.1380 & 0.6823 & 0.9641 & 15.9212 & 43.1345 & 0.7233 \\
\hline \multirow{3}{*}{ Aug. } & Obs & 0.5070 & 0.6984 & 0.9251 & 141.3614 & 370.6189 & 0.5368 \\
\hline & Obs N3 & 0.5096 & 0.5405 & 0.9208 & 150.9307 & 379.4387 & 0.5470 \\
\hline & Pre N3 & 0.5228 & 0.5403 & 0.9183 & 154.3551 & 389.8174 & 0.5521 \\
\hline \multirow{3}{*}{ Nov. } & Obs & 0.0788 & 0.6074 & 0.9607 & 5.0934 & 15.0608 & 0.7080 \\
\hline & Obs N3 & 0.0791 & 0.6891 & 0.9757 & 5.5730 & 14.9612 & 0.7827 \\
\hline & Pre N3 & 0.0774 & 0.6599 & 0.9731 & 5.7229 & 15.4960 & 0.7670 \\
\hline
\end{tabular}


겨울 중 각각 2월, 5 월, 8 월, 11 월을 대표적으로 나타내었다. Table 2에서도 확인할 수 있듯이, Obs N3뿐만 아니라 Pre $\mathrm{N} 3$ 또한 Obs와 서로 잘 일치하고 있음을 살펴볼 수 있다.

\section{3 현재대비 미래기간 강우량 변화 분석}

본 연구에서는 RCP 시나리오에서 제공하는 4 개의 시나리 오 중 RCP 8.5 시나리오의 일 강우자료를 2 개의 미래 기간 (Future 1 N3: 2020-2054, Future 2 N3: 2054-2088)으로 나누 어 시간자료를 생성 하였다. Fig. 6 에 모의된 시간강우자료를 이용하여 현재대비 월별 미래 강우량의 변화율(\%)을 도시하 였다. 부산과 서울지역 모두 미래로 갈수록 계절적 편차가 많음을 살펴볼 수 있다.

Fig. 7에 계급구간별 강우량을 도시하였다. 계급구간별 강우량을 살펴보기 위해서는 연속적인 강우시계열로부터 개별적인 강우사상을 분리가 필요하다. 강우사상의 분리는 IETD (Inter Event Time Definition)방법을 사용하였다. Adams and Papa(2000)에 따르면 도시유역에서는 IETD를 6시간으로 결정하는 것이 적당하다는 선행연구를 통해 부산과 서울지역을 IETD 6시간으로 나누어 강우사상을
분리한 다음, 강우사상별 강우량을 계급구간별로 나누어 분석하였다.

부산과 서울지역의 현재대비 미래 강우량의 변화율을 살펴본 결과, 부산지역의 경우 $10 \sim 40 \mathrm{~mm}$ 계급구간에서 Future 1 은 $1.56 \%$ 감소, Future 2 는 $5.07 \%$ 증가하는 것으로 확인되었다. $100 \mathrm{~mm}$ 이상의 극한강우는 현재대비 Future 1 은 $35.13 \%$ 증가, Future2는 $46.72 \%$ 증가하는 것으로 분석되었다. 서울지역의 경우 $10 \sim 40 \mathrm{~mm}$ 계급구간에서 Future 1 의 경우 $7.08 \%$ 감소, Future 2 의 경우 $2.28 \%$ 감소하 는 것으로 확인되었다. $100 \mathrm{~mm}$ 이상의 경우 Future 1은 $11.79 \%$ 감소, Future 2 는 $5.74 \%$ 감소하고 있음을 살펴볼 수 있다. 부산지역의 경우 강우구간별로 전반적으로 현재대 비 증가하는 경향이 있는 것으로 분석되고 있으며, 이와 반대로 서울지역의 경우에는 현재대비 미래의 강우량은 약간 줄어드는 것으로 분석된다.

\section{4 미래 강우유출수 결과}

부산지역의 일 강우자료를 통해 모의한 시간강우자료를 부산 녹산공단지역의 EPA-SWMM의 입력 자료로 사용하여

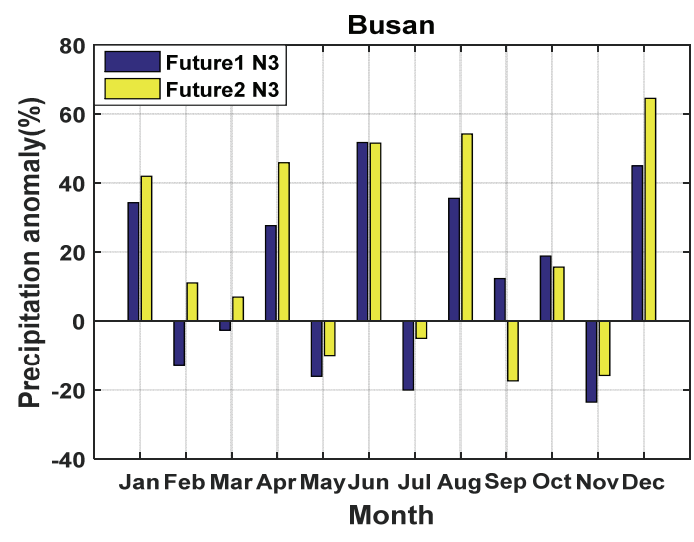

(a) Busan

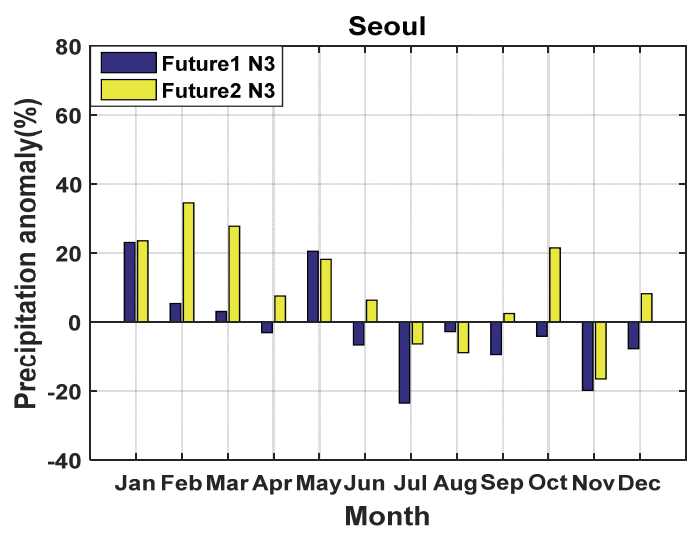

(b) Seoul

Fig. 6. Monthly Change Rate of Future Rainfall

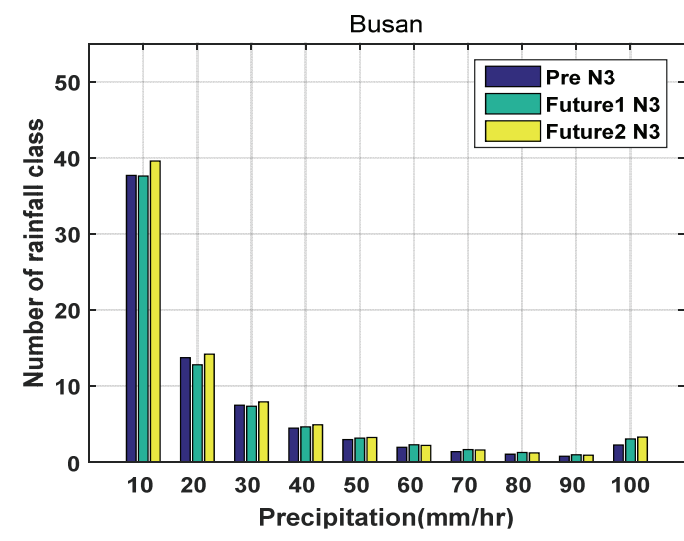

(a) Busan

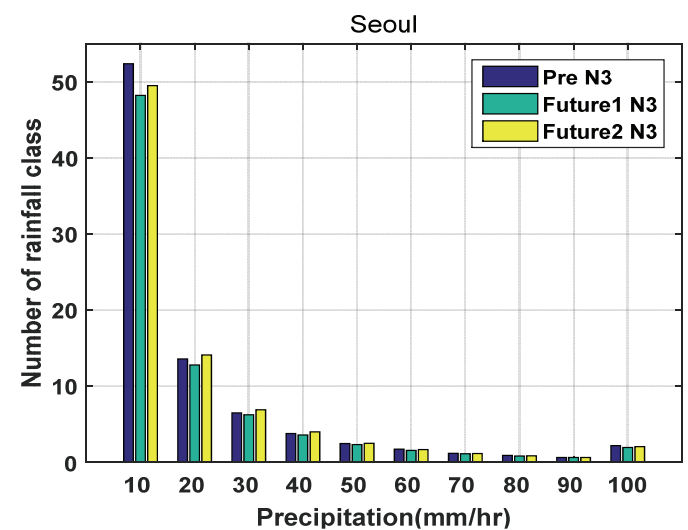

(b) Seoul

Fig. 7. Future Rainfall Change by $10 \mathrm{~mm}$ Interval Class in Busan and Seoul 
Table 3. Annual Average Runoff of Busan Noksan

\begin{tabular}{c|c|c|c}
\hline Busan Noksan & Obs & Obs N3 & Pre N3 \\
\hline Annual Mean Runoff $(m m / y r)$ & 1386.718 & 1387.818 & 1387.283 \\
\hline
\end{tabular}

강우유출수를 모의하였다. Table 3은 Obs, Obs N3, Pre N3의 연 평균 강우유출수를 비교한 것이다. 비교 결과, Obs N3 및 Pre N3의 연 평균 강우 유출수가 Obs를 우수하게 재현하는 것으로 나타났다. 따라서 본 연구에서 적용한 미래 일 강우자 료로부터 NSRPM3를 이용하여 미래 시간강우자료를 생산 하여 미래 강우유출수를 모의하는 것이 타당성이 있는 것으 로 분석되었다.

Fig. 8(a)는 현재대비 미래 월별 강우유출수 변화율을 보여주고 있다. Fig. 9(a)에서 살펴볼 수 있듯이 대부분의 월별 강우유출수는 미래로 갈수록 현재보다 증가할 것으로 전망되었다. Fig. 8(b)에 월별 평균 첨두 일 유출고을 도시하 였다. Fig. 8(b)에서 살펴볼 수 있듯이 대부분의 월별 첨두 일 유출고는 미래에 증가하는 것으로 나타나고 있다. 특히
Future 2의 경우 현재기간보다 여름철 첨두 일 유출고의 증가 폭이 매우 큰 것을 살펴볼 수 있으며, 이로부터 Future 2 기간에는 홍수위험도가 현재보다 매우 높아질 가능성이 큰 것으로 분석되었다.

현재 대비 미래 연 평균 강우유출수의 변화율은 Future 1 의 경우 현재 대비 연 평균 $12.61 \%$ 증가하는 것으로 나타났 고, Future 2 의 경우 $17.56 \%$ 증가 하는 것으로 나타났다. 이는 미래 모의자료의 불확실성과 월별 강우유출수의 변동 성을 고려하더라도, 미래로 갈수록 강우유출수의 증가 추세 가 비교적 명확함을 보여준다고 할 수 있다.

Fig. 9에 현재기간 모의자료 및 Future 1과 Future 2의 모의자료를 통해 나온 강우유출수의 유황곡선을 도시하였 다. Fig. 9를 통해 알 수 있듯이, Future 1과 Future 2 기간

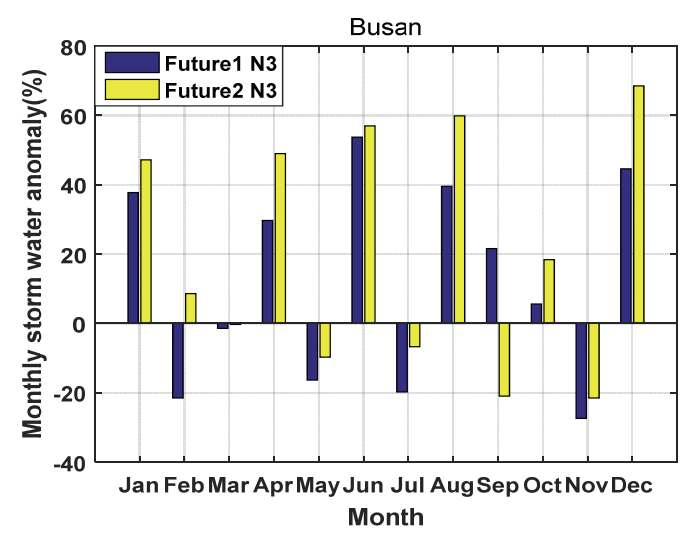

(a) Monthly Stormwater Depth

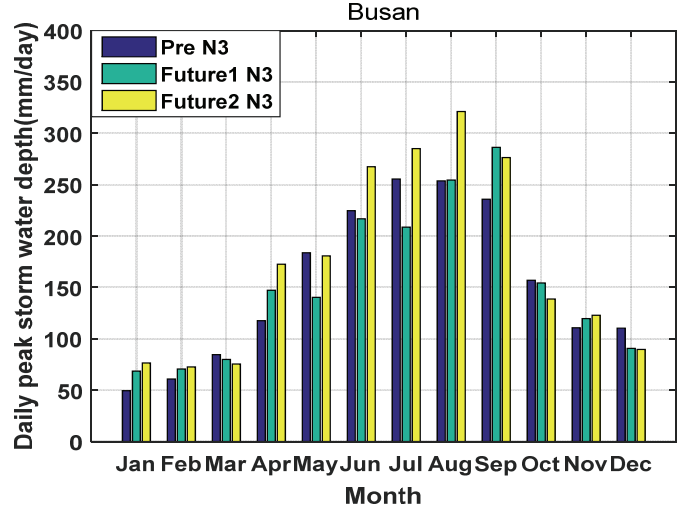

(b) Daily peak stormwater depth

Fig. 8. Changes in Future Storm Water Relative to Present

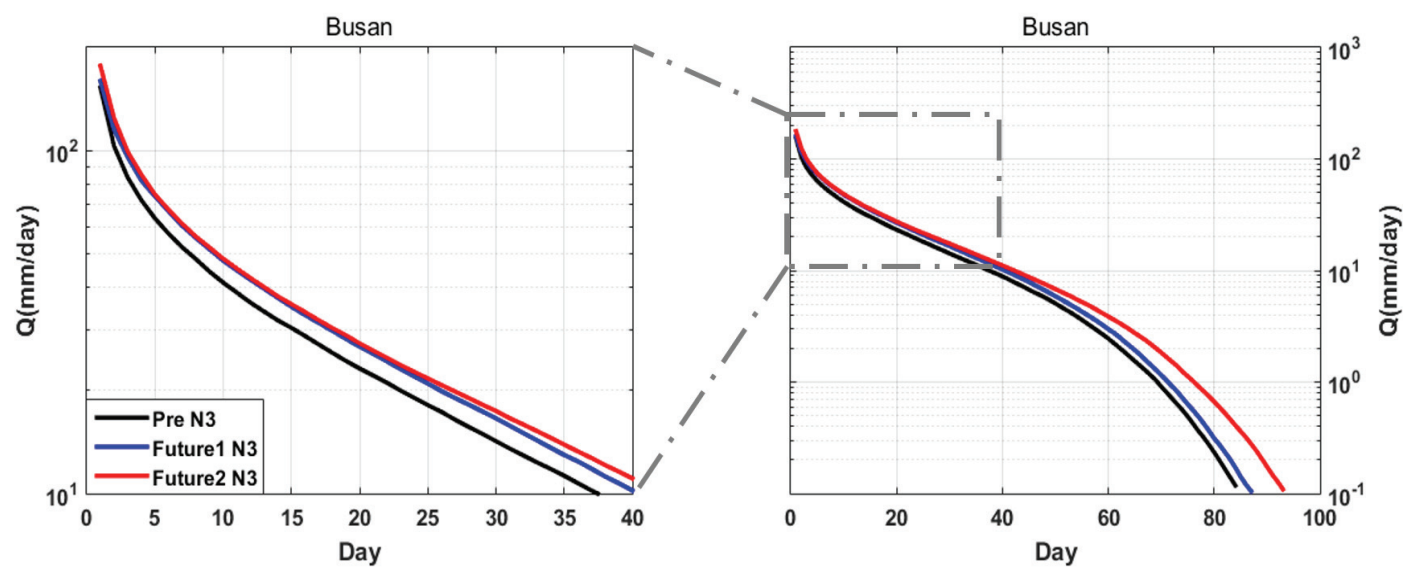

Fig. 9. Flow Duration Curves for Present and Future Periods 
동안의 강우유출수가 현재기간 강우유출수에 비해 크게 산출되고 있음을 알 수 있으며, 미래로 갈수록 강우유출수의 양이 증가하고 있음을 살펴볼 수 있다. 이와 같은 전반적인 유황에서의 증가는 $100 \mathrm{~mm}$ 이상의 극한강우사상이 증가하 는 전망결과와 연계되어 강우 시에 부산지역의 합류식 하수 관거 월류수가 현재보다 많이 질 것이라는 예상을 해 볼 수 있을 것이다. 따라서 추후 부산지역의 경우 이에 대한 대비가 필요할 것으로 판단된다. 또한, Future 1과 Future 2 기간 동안에 부산 도시하천에 최소한의 수량이 확보되는 날이 더 많이 질 것이라는 전망을 해 볼 수 있을 것이다. 따라서 최근 도입되고 있는 LID 시설 등을 통하여 도시 하천의 수질이 양호하게 확보될 수 있다면 미래에는 현재보 다 양호한 수생태계 서식환경을 조성하는데 보다 유리한 환경을 가질 수 있을 것으로 판단된다.

\section{4. 결 론}

본 연구에서는 미래 기후자료에서 제공하는 일 강우자료를 시간강우자료로 만들기 위해 추계학적 점강우모형 중 하나인 NSRPM3 를 적용하여 미래 강우량의 변화양상을 확인하고, 모의된 시간강우자료를 EPA-SWMM의 입력자료로 활용하 여 미래 강우유출수의 변화를 살펴보고자하였다. 우선 기상 청 RCM을 통하여 획득된 RCP 8.5 기후변화 시나리오에 따른 미래모의 기후자료로부터 편이보정 과정을 통하여 현재 기간 및 미래기간의 기후자료(일 강우자료 및 일 평균 기온)를 생산하였다. 생산된 미래 일 강우자료로부터 NSRPM3를 이용하여 시간단위의 강우자료를 생산하였다.

생산된 미래 시간강우자료에 IETD 6시간을 적용하여 강우사상별로 분리하여 $10 \mathrm{~mm}$ 의 계급구간으로 살펴보았을 때, 부산지역의 경우 강우량이 거의 모든 구간에서 현재보다 증가할 것으로 전망되었으나, 서울지역의 경우에는 현재대 비 다소 감소하는 것으로 나타났다. 특히 부산지역의 경우에 는 $100 \mathrm{~mm}$ 가 넘는 극한강우사상이 현재보다도 $30 \%$ 이상 증가할 것으로 전망되어졌다. 따라서 도시지역의 극한강우 사상으로 인한 홍수위험성의 증가에 대비할 필요가 있을 것으로 판단되었다.

모의한 미래 시간강우자료를 입력 자료로 사용하여 부산 녹산공단지역을 대상으로 EPA-SWMM 모형을 구축하여 미래 강우유출수를 살펴본 결과, 월별 일 최대 강우유출수의 경우 미래에는 매우 크게 증가되는 것을 확인할 수 있었다. 또한, 미래 강우유출수의 평균적인 유황을 살펴본 결과 모든 구간에서 유황이 현재보다 증가하는 것으로 나타났다. 따라 서 홍수위험성 증가와 더불어서 합류식 하수관거 월류수를 비롯한 비점오염원의 배출이 더 증가할 가능성이 높을 것으 로 전망되었다.

본 연구를 통하여 강우유출수를 모의하기 위하여 점강우 모형을 이용한 일 강우자료로부터 시간강우자료의 생산이
가능함을 살펴볼 수 있었으며, 이러한 방법론은 장기간의 강우유출수 정보가 필요한 수공구조물 설계 또는 도시하천 수질관리대책 수립 시에 기후변화를 고려한 모델링 과정에 적용 가능할 것으로 기대된다.

\section{감사의 글}

본 연구는 국토교통과학기술진흥원 지원 국토교통기술 화사업지원(17TBIP-C111520-02)의 연구비 지원으로 수행 되었습니다. 이에 감사드립니다.

\section{References}

Adams, B.J., and Papa, F. (2000) Urban Stormwater Management Planning with Analytical Probabilistic Models. John Wiley \& Sons Inc.

Choe, B., Lee, O., Park, Y., Im, T., and Kim, S. (2016) Quantifying Uncertainty in Korean Non-point Soruces Pollution Control Facilities Design Practice. J. Korean Soc. Hazard Mitig., Vol. 16, No. 5, pp. 359-367. Cowpertwait, P.S.P., O’Connel, P.E., Metcalfe, A.V., and Mawdsley, J.A. (1996) Stochastic Point Process Modeling of Rainfall: 1. Single-site Fitting and Validation. Journal of Hydrology, Vol. 175, pp. 17-46.

Gupta, H.V., Kling, H., Yilmaz, K.K., and Martinez, G.F. (2009) Decomposition of the Mean Squared Error and NSE Performance Criteria: Implications for Improving Hydrological Modelling. Journal of Hydrology, Vol. 377, No. 1, pp. 80-91.

Kim, B.S., Kim, B.K., Kyung, M.S., and Kim, H.S. (2008) Impact Assessment of Climate Change on Extreme Rainfall and IDF Analysis. Journal of Korea Water Resources Association, Vol. 41, No. 4, pp. 379-394.

Kim, E., Choi, H.I., Park, M.J., Cho, S.J., and Kim, S. (2011) The Effect of Climate Change on Korean Drought Occurrences using a Stochastic Soil Water Balance Model. Scientific Research and Essays, Vol. 6, No. 13, pp. 2771-2783.

Kim, S., Han, S., and Kavvas, M.L. (2008) Analytical Derivation of Steady-state Soil Water Probability Density Function Coupled with Simple Stochastic Point Rainfall Model. Journal of Hydrologic Engineering, Vol. 13, No. 11, pp. 1069-1077.

Lee, O., Choi, J., Jang, S., and Kim, S. (2017) Application of Stochastic Point Rainfall Model for Temporal Downscaling of Daily Precipitation Data. J. Korean Soc. Hazard Mitig., Vol. 17, No. 1, pp. 323-337. 
Lee, O., Park, Y., Kim, E., and Kim, S. (2016) Projection of Korean Probable Maximum Precipitation under Future Climate Change Scenarios. Advances in Meteorology, Vol. 2016, 3818236.

Rodriguez-Iturbe, I. (1986) Scale of Fluctuation of Rainfall Models. Water Resources Research, Vol. 22, No. 9, pp. 15-37.

Zahmatkesh, Z., Karamouz, M., Goharian, E., and Burian, S.J. (2014) Analysis of the Effects of Climate Change on Urban Storm Water Runoff using Statistically Downscaled Precipitation Data and a Change Factor Approach. Journal of Hydrologic Engineering, Vol. 20, No. 7, 05014022.

\begin{tabular}{l|l} 
Received & October 18, 2017 \\
Revised & October 23, 2017 \\
Accepted & November 16, 2017
\end{tabular}

